\title{
Synthesis of Glutamate-Zinc-Aluminium-Layered Double Hydroxide Nanobiocomposites and Cell Viability Study
}

\begin{abstract}
A layered compound of zinc-aluminium layered double hydroxide (LDH) to be used as a host for a guest amino acid, glutamate was synthesized. Different parameters were used and optimized to form amino acid-intercalated pure phase materials. The resulting Bio-Inorganic Nanohybrid (BINH) was chosen for further characterization. BINH exhibits the glutamate to be in vertical or perpendicular orientation to the inorganic layer. Cytotoxicty test indicates that the IC50 value was observed at $3.125 \mu \mathrm{g} / \mathrm{ml}$. Results from this study will be used in the development of a new delivery system for therapeutic agents comprising amino acids or peptides.
\end{abstract}

Keyword: Nanobiotechnology, glutamate, layered double hydroxide, bio-inorganic nanohybrid 